\title{
A PIRÓLISE COMO TÉCNICA ANALÍTICA
}

Flaviano Oliveira Silvério e Luiz Cláudio Almeida Barbosa*

Departamento de Química, Universidade Federal de Viçosa, 36570-000 Viçosa - MG, Brasil

Dorila Piló-Veloso

Departamento de Química, Universidade Federal de Minas Gerais, 31270-901 Belo Horizonte - MG, Brasil

Recebido em 16/4/07; aceito em 31/10/07; publicado na web em 7/8/08

PYROLYSIS AS AN ANALYTICAL TECHNIQUE. In this paper historical aspects of analytical pyrolysis, the equipment used, the fundamentals and the mechanisms of pyrolysis of different polymeric materials are discussed. The latest work on analytical pyrolysis applied to various types of synthetic and natural samples is reviewed. Current applications of this technique that are discussed include identification of microorganisms, analysis of trace compounds by forensic laboratories, investigation of food and agricultural products, study of the chemical composition of wood, authentication and conservation of artworks, and the study of environmental and geochemical samples.

Keywords: Py-GC-MS; degradation mechanism; polymeric materials.

\section{INTRODUÇÃO}

A palavra pirólise possui origem grega e significa "decomposição pelo calor", ou seja, a degradação de um material por energia térmica. No entanto, pirólise analítica é uma técnica de caracterização de determinado material, na ausência de oxigênio, pelas reações de degradação químicas induzidas por energia térmica. ${ }^{1}$ Esse processo resulta em um conjunto de pequenas espécies moleculares, as quais são relacionadas à composição da amostra original. ${ }^{1,2}$

Essas pequenas moléculas são usadas para identificar qualitativamente a estrutura original de macromoléculas, por meio de padronização própria e adequada, e para fornecer informação quantitativa da sua composição. ${ }^{3}$

A pirólise qualitativa caracteriza-se por ser uma técnica em que constantemente se realizam comparações de pirogramas de referência (impressões digitais) com pirolisados de interesse. ${ }^{4}$ Nesse tipo de análise, a reprodutibilidade dos resultados é obtida quando os parâmetros que levam à formação desses pirolisados são minuciosamente controlados e otimizados para um sistema polimérico investigado, pois esses influenciam diretamente nos mecanismos de degradação térmica. ${ }^{5}$ Em amostras poliméricas, os mecanismos dessas fragmentações podem ocorrer via eliminação de pequenas moléculas, cisão de cadeia (despolimerização) ou clivagem aleatória. ${ }^{6}$

Como a degradação térmica de macromoléculas freqüentemente produz misturas complexas de moléculas menores, é necessário o uso associado de outras técnicas, como a cromatografia em fase gasosa, para promover a separação das espécies produzidas. ${ }^{7}$ Quando essa associação ou acoplamento inclui também a espectrometria de massas, as espécies produzidas podem ser ainda identificadas (Figura 1).

Se a degradação resultar em reações secundárias indesejáveis resultando em sinais mais alargados, ${ }^{8}$ ou se ocorrer perdas de produtos de degradação durante a transferência do pirolisador para o sistema cromatográfico, ${ }^{9}$ a alternativa mais indicada é o acoplamento do pirolisador diretamente ao espectrômetro de massas, originando a técnica de análise conhecida pela sigla Pi-EM. ${ }^{10}$

Esta revisão foi motivada pela escassa literatura em português sobre esse tema. Assim, este artigo objetiva apresentar os fundamentos

*e-mail: lcab@ufv.br

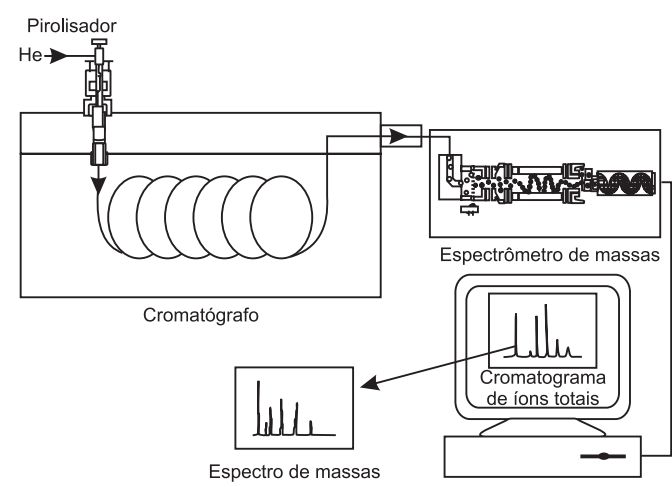

Figura 1. Sistema de Pi-CG-EM usando pirolisador de microforno equipado com cromatógrafo a gás e espectrômetro de massas com quadrupolo

da pirólise como técnica analítica e investigativa, bem como discutir sobre análises qualitativa e quantitativa e sobre algumas limitações e diversos campos de aplicação da técnica.

\section{ASPECTOS HISTÓRICOS DA PIRÓLISE ANALÍTICA}

A pirólise como ferramenta analítica e seu desenvolvimento são detalhadamente relatados na literatura há vários anos. ${ }^{11}$

Em 1948, foi publicado o primeiro trabalho da pirólise acoplada à espectrometria de massas off-line (Pi-EM) de polímeros. ${ }^{11,12}$ Bradt et $a l .{ }^{13}$ realizaram, sob vácuo, a Pi-EM on-line de amostras de polímeros, obtendo informações sobre suas estruturas.

Posteriormente, Davison et al. ${ }^{14}$ também divulgaram trabalhos sobre pirólise acoplada à cromatografia em fase gasosa (Pi-CG) offline de polímeros, demonstrando de maneira definitiva a eficiência desta técnica na caracterização de materiais poliméricos.

Com o desenvolvimento de sistemas "on-line" de Pi-CG, novas aplicações em análises de polímeros foram propostas simultaneamente por três grupos distintos de trabalhos: Lehrle e Rob, ${ }^{15}$ Radell e Strutz ${ }^{16}$ e Martin, ${ }^{17}$ ocorrendo, conseqüentemente, um aumento significativo do número de publicações nessa área.

Vallmin et al. ${ }^{18}$ publicaram a primeira descrição do sistema totalmente acoplado Pi-CG-EM, usando o pirolisador de Ponto de Curie acoplado 
à cromatografia em fase gasosa e a um espectrômetro de massas.

Apesar do surgimento do detector de alta sensibilidade por ionização em chama (FID) e do acoplamento da CG à espectrometria de massas em 1965, somente em 1979, com o advento da coluna capilar de sílica fundida, observou-se um grande progresso no uso dessa técnica. ${ }^{19,20}$

Com os avanços tecnológicos de novos pirolisadores e a precisão no controle das condições de operação, ficou mais fácil obter dados reprodutíveis nas análises por pirólise. ${ }^{20}$ Assim, a padronização e compilação de dados em um banco, com várias amostras-padrão são importantes para comparação interlaboratorial de dados de pirólise analítica. Tsuge e Ohtani ${ }^{21}$ realizaram uma tentativa de padronizar um banco de dados com 135 espécies de polímeros típicos analisados usando-se Pi-CG. Em 1992, foi publicada a versão chinesa desse trabalho. ${ }^{22}$

Um grande avanço na análise de moléculas de diferentes tipos foi alcançado desde que se estabeleceu o uso de uma técnica aplicada a volatilizar amostras de qualquer natureza acoplada a outras técnicas de separação e de identificação. De 1948 aos dias atuais, os acoplamentos de um sistema de degradação térmica (pirólise) a um espectrômetro de massas e a um cromatógrafo gasoso resultaram, respectivamente, nas técnicas conhecidas como pirólise acoplada à espectrometria de massas (Pi-EM) e pirólise acoplada à cromatografia em fase gasosa (Pi-CG). Da combinação dessas três técnicas, surgiu a pirólise acoplada à cromatografia em fase gasosa e à espectrometria de massas (Pi-CG-EM). Amostras que não podem ser analisadas por CG-EM, em virtude da sua dificuldade de volatilização, podem ser facilmente estudadas por pirólise analítica. ${ }^{2,10}$

Atualmente, a pirólise analítica é extensivamente utilizada, particularmente as técnicas Pi-EM, Pi-CG e Pi-CG-EM, em que a caracterização de amostras é feita com análises separativas dos pi-

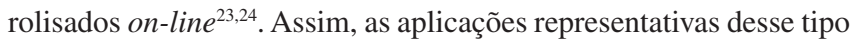
de pirólise são encontradas em vários campos, como na química de polímeros, bioquímica, geoquímica, nas ciências da madeira, forense, de alimentos, ciência ambiental e conservação de energia; na toxicologia e nos estudos de amostras de origem extraterrestre etc. ${ }^{24-26}$

\section{ASPECTOS QUÍMICOS DA PIRÓLISE}

Em estudos de pirólise analítica, o processo é realizado sob vácuo ou atmosfera de gás inerte, como hélio ou nitrogênio, sendo as reações pirolíticas primárias importantes para análise ou determinação estrutural. ${ }^{27}$

As espécies primárias formadas na pirólise são principalmente produtos de eliminação simples ou de radicais formados por clivagem homolítica de ligações químicas..$^{25,28}$ Se os radicais saem da zona de aquecimento rapidamente, eles não têm tempo para reagir com o material não-pirolisado ou entre si, evitando reações secundárias indesejáveis. ${ }^{29}$ Nessas condições, os resultados são mais reprodutíveis, o que é ideal para análises quantitativas. ${ }^{30}$

Se o aquecimento for lento ou as amostras forem grandes, há a possibilidade de os materiais iniciais da pirólise (radicais) reagirem entre si ou com outros não-pirolisados, à medida que se difundirem fora do corpo da amostra. ${ }^{29,30}$

Se os parâmetros do aquecimento (razão de aquecimento e temperaturas inicial e final) e o tamanho da amostra são controlados, pode-se esperar que os pirolisados complexos sejam semelhantes ao se compararem amostras de uma mesma substância, sendo essa a base para a pirólise analítica. ${ }^{21,30}$

\section{Tipos de reações de degradação térmica}

Nos experimentos de degradação térmica de polímeros discutidos na literatura, destacam-se três tipos de reações de fragmentação: cisão aleatória de cadeia, ${ }^{31,32}$ cisão de cadeia lateral ${ }^{33}$ e despolimerização ou unzipping. ${ }^{34-37}$
Em cisões aleatórias de cadeia, as ligações da "espinha dorsal" do polímero (parte do polímero que dá sustentação ou organização e que constitui sua estrutura central ou principal) são quebradas, produzindo pequenos fragmentos. As poliolefinas são bons exemplos de materiais que se comportam desta maneira. O polietileno, por exemplo, quando é suficientemente aquecido, produz principalmente hidrocarbonetos com diferentes números de átomos de carbono ${ }^{25}$ (Figura 2).

Na cisão de cadeia, o hidrocarboneto polimérico é transformado em radicais terminais, que podem ser estabilizados pela abstração de um hidrogênio de uma molécula vizinha, formando assim um novo radical que também pode ser estabilizado de diversas maneiras. A cisão beta é o principal mecanismo de estabilização. ${ }^{25}$

Este processo acontece de modo contínuo, resultando em hidrocarbonetos saturados e insaturados, com uma ou duas ligações duplas (em cada extremidade). ${ }^{25} \mathrm{O}$ pirograma de uma poliolefina é muito característico, pois se apresenta como sucessivos tripletos representando um dieno, alqueno e alcano, os quais eluem nesta ordem (expansão da Figura 2). A próxima seqüência de três picos contém um carbono a mais, como mostrado na Figura 2.

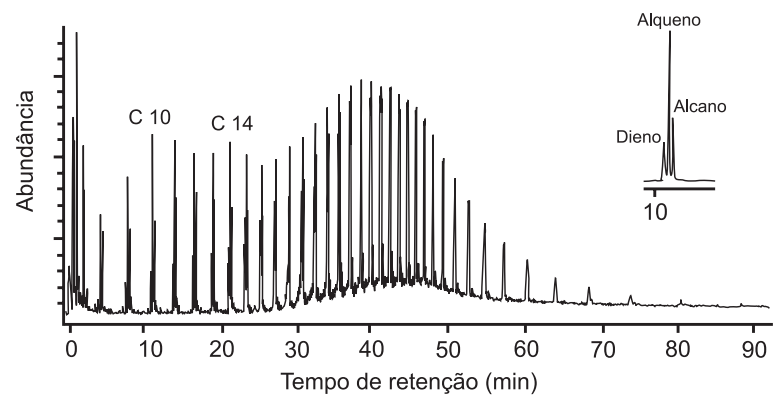

Figura 2. Pirograma do polietileno obtido a $750{ }^{\circ} \mathrm{C}^{40}$

A cisão de grupos laterais ocorre quando as ligações dos substituintes ligados à cadeia polimérica são mais fracas que as da "espinha dorsal" do polímero. Assim, os grupos laterais são separados, levando a alterações na cadeia principal. Esta, como conseqüência, poderá ser rompida em temperaturas elevadas. A pirólise do poli(cloreto de vinila) é um bom exemplo em que esse tipo de degradação acontece. Nesse caso, ocorre a eliminação de ácido clorídrico (grupo lateral), acompanhada da clivagem da cadeia carbônica, com formação de compostos aromáticos ${ }^{37,38}$ (Figura 3 ).

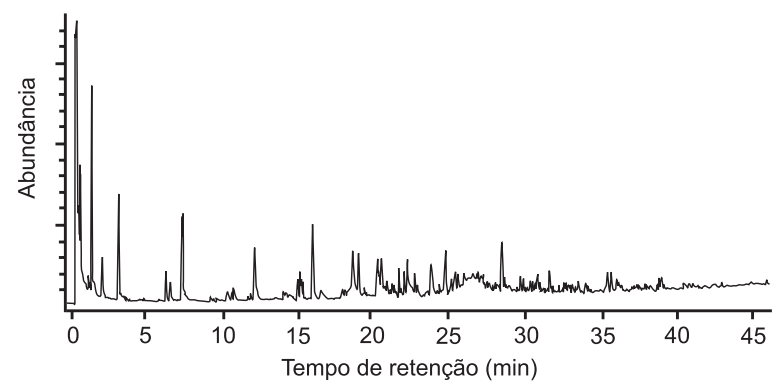

Figura 3. Pirograma do poli(cloreto de vinila) a $610{ }^{\circ} \mathrm{C}^{40}$

A despolimerização (unzipping) constitui um terceiro tipo de processo pelo qual o polímero se transforma quase integralmente em monômeros. Em temperatura abaixo de $550{ }^{\circ} \mathrm{C}$, não ocorre nenhuma fragmentação do poli(tetrafluoreteno) (Teflon). Entretanto, quando aquecido entre 600 e $700{ }^{\circ} \mathrm{C}$, o poli(tetrafluoreteno) se degrada produzindo apenas o monômero tetrafluoreteno. ${ }^{39} \mathrm{O}$ pirograma do teflon obtido a 600 ${ }^{\circ} \mathrm{C}$ é apresentado na Figura 4. Já acima de $700{ }^{\circ} \mathrm{C}$ ocorre fragmentação, resultando na formação de apenas um produto, sendo este identificado por espectrometria de massas como 1,1,2,3,3,3-hexafluoropropeno. ${ }^{40}$ 
Resultados semelhantes foram obtidos por Bhadury et al, ${ }^{39}$ que estudaram a influência da temperatura sobre a degradação do poli(tetrafluoreteno), sendo seus resultados apresentados de forma resumida na Figura 5.

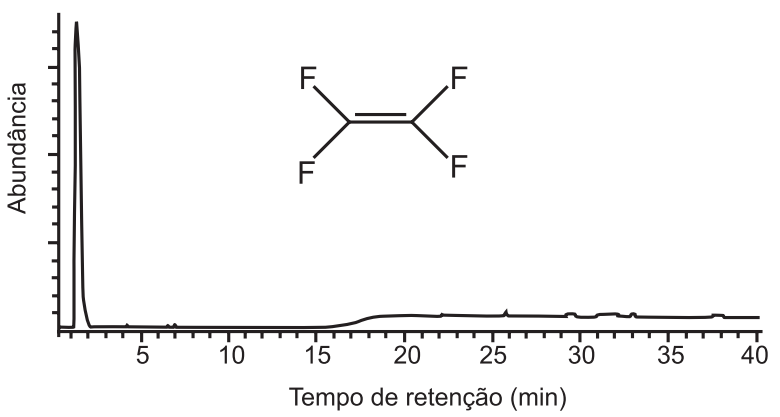

Figura 4. Pirograma do poli(tetrafluoreteno) a $600{ }^{\circ} \mathrm{C}^{40}$

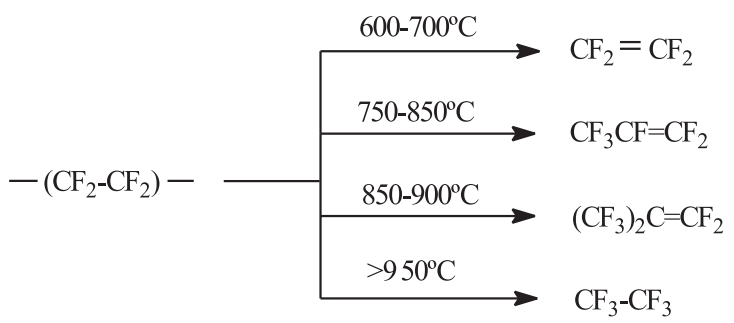

Figura 5. Produtos de pirólise do poli(tetrafluoreteno) em diferentes temperaturas ${ }^{40}$

Como citado anteriormente, durante a pirólise as moléculas podem reagir das seguintes maneiras: fragmentando-se de forma aleatória (cisão de cadeia), formando monômeros, dímeros, trímeros, tetrâmeros e pentâmeros; de forma única, produzindo apenas monômeros (despolimerização); ou por meio da eliminação de grupos ligados à cadeia principal. A seguir, será apresentado um exemplo do mecanismo dessas reações (Figura 6).

\section{Proposta mecanística de formação de tetrâmeros via estereo- isomerização}

A análise dos tetrâmeros provenientes da pirólise de polímeros é muito útil na caracterização das suas propriedades físicas, como é o caso da taticidade, que se refere à organização espacial dos monômeros em uma cadeia polimérica. De acordo com a orientação dos monômeros, os polímeros podem ser classificados em atáctico, isotáctico, táctico e sindiotáctico. Cada um desses polímeros apresenta pirograma característico de acordo com sua taticidade, o que pode ser observado principalmente na região dos tetrâmeros. O mecanismo de formação dessas espécies foi estudado por vários autores, ${ }^{41-43}$ que explicaram a estereoisomerização dos produtos de degradação durante a pirólise do poliestireno isotáctico (Figura 6).

Pode-se observar (Figura 6) que, inicialmente, ocorre cisão aleatória com formação de macrorradicais primários e secundários, que se decompõem em monômeros. Alguns dímeros e trímeros também são formados por meio de rearranjos envolvendo transferência 1,5 de hidrogênio, seguida de cisão- $\beta$. Já na formação de tetrâmeros, ocorre adicionalmente uma segunda transferência 1,3 de hidrogênio, seguida pela cisão- $\beta{ }^{44}$

No exemplo mostrado na Figura 6, o quinto carbono do macrorradical II é um centro tetraédrico, que se transforma em trigonal plano (o carbono reibridiza para $\mathrm{sp}^{2}$ ), após a transferência radicalar 1,5. Assim, quando esse carbono $\mathrm{sp}^{2}$ é novamente reibridizado para $\mathrm{sp}^{3}$, por intermédio do rearranjo radicalar 1,3 , são formadas quantidades iguais dos dois tetrâmeros $(\mathrm{r}-$ isômero racêmico e $\mathrm{m}$ - isômero

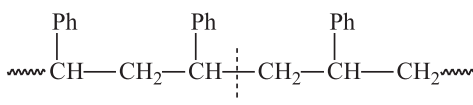

Isopoliestireno (I)
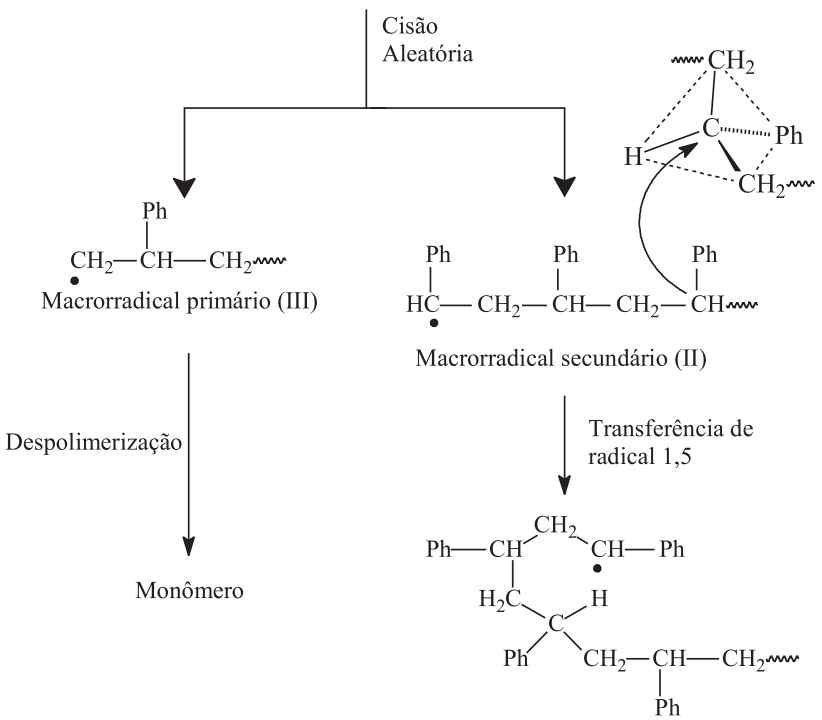

Intermediário de seis membros (IV)
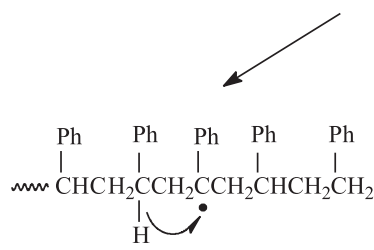

Macrorradical transferido 1,5 (V)
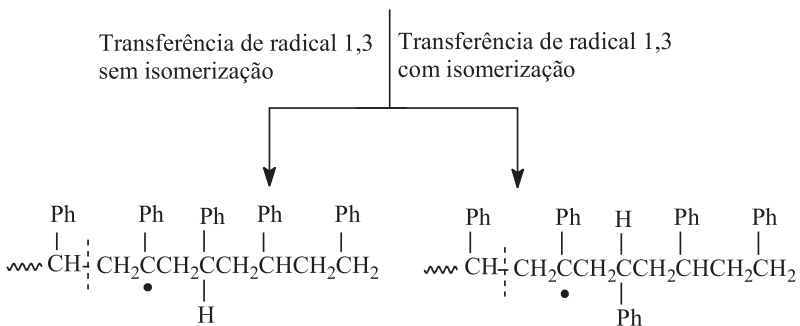

Macrorradical transferido 1,3 (1) (VI)

Macrorradical transferido 1,3 (2) (VII)
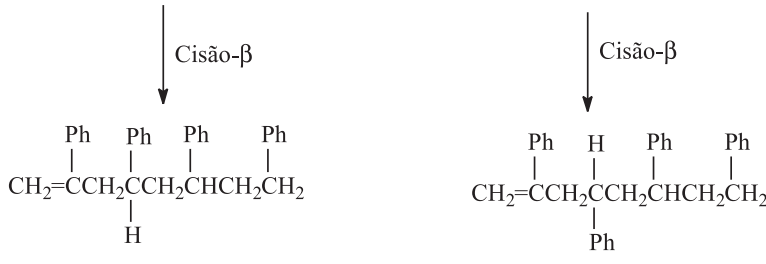

m-tetrâmero (VIII)

r-tetrâmero (IX)

Figura 6. Mecanismo de formação de tetrâmeros por estereoisomerização, por meio de reações de transferência radicalar durante a pirólise do poliestireno

meso). ${ }^{44}$ Além disso, o mecanismo de transferência de radical, que envolve estereorregularidade seguida pela cisão simples e terminação, mantém a taticidade original.

\section{PIROLISADORES}

O instrumento para o desenvolvimento da pirólise é denominado pirolisador, sendo comercialmente classificado como de modo contí- 
nuo e pulsado. O primeiro inclui os de fornos ou microfornos (Figura 7a), e são pré-aquecidos na temperatura da pirólise final, antes da introdução da amostra. ${ }^{7,8,45}$ Já os de modo pulsado incluem sistema usando filamento resistivamente aquecido, ou metal ferromagnético indutivamente aquecido com radiofreqüência (Figura 7b). O último é chamado de pirolisador de Ponto de Curie (PC). Há ainda outro tipo de pirolisador, não rotineiramente usado para pirólise de polímeros, que é o de sistema de pirólise a laser. ${ }^{45}$
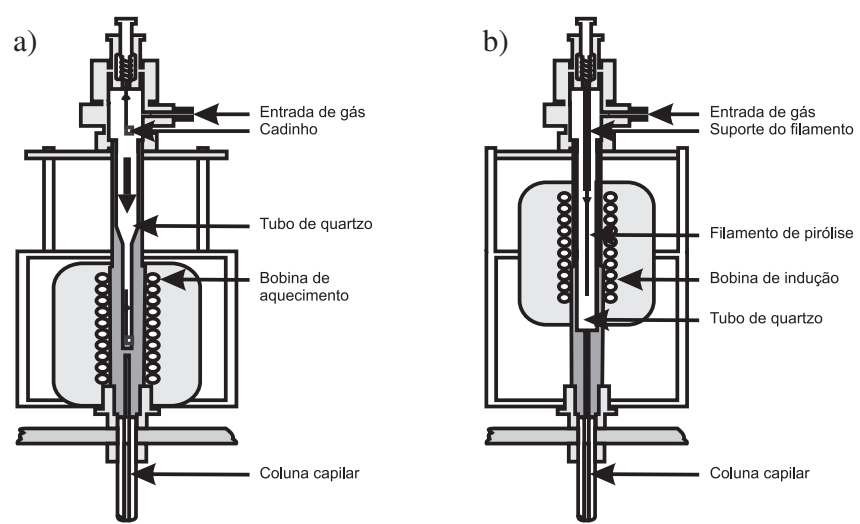

Figura 7. (a) Pirolisador de microforno e (b) Pirolisador de Ponto de Curie

\section{Pirolisador de microforno}

O pirolisador de microforno (Figura 7a) caracteriza-se por ser aquecido previamente, sem a presença da amostra, na temperatura desejada. Em seguida, o cadinho contendo a amostra a ser pirolisada é lançado no reator (tubo de quatzo). A quantidade de amostra deve ser extremamente pequena, geralmente menor que $0,1 \mathrm{mg}$, para facilitar o seu aquecimento. Anderson e Ericson ${ }^{46}$ discutem os efeitos do tamanho das partículas da amostra na reprodutibilidade dos resultados da pirólise, e Wampler e Levy ${ }^{30}$ relatam, além dos efeitos do tamanho das partículas das amostras, a influência da sua geometria, a contaminação e outras variáveis na reprodutibilidade dos dados de pirólise.

\section{Pirolisador de Ponto de Curie (PC)}

No pirolisador PC (Figura 7b), a amostra é depositada na superfície do filamento com o Ponto de Curie adequado. Em seguida, o metal é aquecido. ${ }^{45,47}$

Quando se empregam pirolisadores PC, é necessário escolher filamento metálico adequado para cada tipo de amostra. ${ }^{47}$ Uma limitação dessa técnica é a mudança nas características térmicas do filamento em razão do excesso de uso ou da utilização de alguns reagentes, que podem danificar a qualidade das pirólises subseqüentes. Por exemplo, ocorre deterioração do filamento de platina por ataque ácido, normalmente ácido clorídrico, a partir da pirólise do polímero do cloreto de vinila. ${ }^{2}$

Em pirolisadores $\mathrm{PC}$, a reprodutibilidade dos fragmentos característicos de polímeros, chamados de produtos da pirólise, é afetada principalmente pela limpeza de partes do sistema. Para uma pirólise de qualidade, a presença de contaminantes pode resultar em efeitos adversos e alterar drasticamente o tipo e a quantidade dos seus produtos. $^{9}$

Para minimizar esse problema, os filamentos podem ser aquecidos na presença de ar a $1.000{ }^{\circ} \mathrm{C}$, para remoção de resíduos orgânicos. Durante a limpeza do fio de Ponto de Curie ou dos filamentos em chama, pode ocorrer a formação de óxidos metálicos, que afetarão resultados de pirólises subseqüentes. Para os sistemas de Ponto de Curie, a posição do fio na bobina de indução também afeta a natureza e a quantidade de produtos de pirólises. ${ }^{27}$

\section{COMO SE OBTER INFORMAÇÃO ANALÍTICA}

\section{Informação qualitativa}

Na Figura 8 apresenta-se um fluxograma geral ilustrando as etapas de uma análise envolvendo a pirólise como técnica analítica.

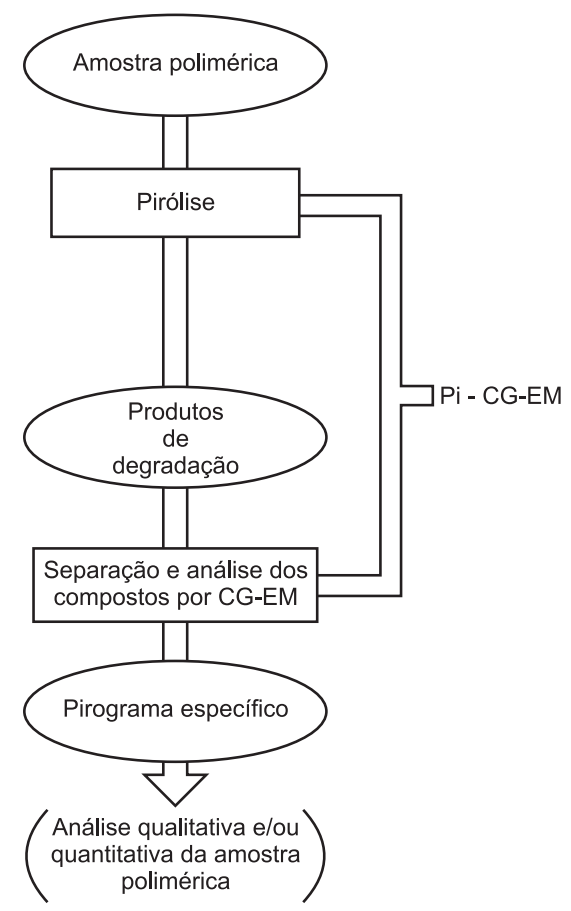

Figura 8. Fluxograma da análise por Pi-CG-EM de amostras poliméricas

Para cada tipo de material polimérico, em dada temperatura obtém-se um pirograma característico..$^{24,25,29} \mathrm{~A}$ identificação qualitativa é realizada por comparação com pirogramas de polímeros-padrão, ambos nas mesmas condições de análise..$^{21,48}$ Essa identificação pode ser confirmada por espectrometria de massas ou por dados da literatura. ${ }^{49}$

Na Tabela 1 são apresentados exemplos de produtos de degradação de vários polímeros sintéticos comumente encontrados em produtos comerciais. Como se observa nessa tabela, os produtos principais gerados em cada caso são característicos de cada material polimérico.

\section{Informação quantitativa}

A abordagem quantitativa em pirólise analítica é mais comum em trabalhos com polímeros, como pode ser observado naquele realizado por Lee et al. ${ }^{50}$ ao estudarem misturas ternárias contendo a borracha natural $(\mathrm{N})$, borracha estireno-butadiento (E) e borracha butadieno (B). O estudo comparou o uso da Pi-CG-EM com outras técnicas de análise como análise termogravimétrica (ATG), calorimetria de varredura diferencial (CVD) e espectroscopia no infravermelho (IV). A técnica Pi-CG-EM mostrou-se mais eficiente que a espectroscopia no infravermelho e a análise termogravimétrica, pois apresentou resultados mais próximos aos esperados, como pode ser verificado na Tabela 2. Já a CVD não permitiu a quantificação de todas as misturas, devido a comportamentos térmicos semelhantes. 
Tabela 1. Reações e produtos característicos da pirólise dos principais polímeros sintéticos

\begin{tabular}{|c|c|}
\hline Polímero & Principais produtos da pirólise \\
\hline Poliisopreno $^{a}$ & Isopreno, dipenteno \\
\hline Polibutadieno $^{\text {a }}$ & $\begin{array}{l}\text { Buta-1,3-dieno,4-vinilciclo- } \\
\text { exeno }\end{array}$ \\
\hline Borrachas com grupo butila $^{a}$ & Isobutileno \\
\hline Borrachas com grupo nitrila ${ }^{a}$ & Buta-1,3-dieno, acrilonitrila \\
\hline Poliestireno $^{a}$ & Estireno, oligômeros \\
\hline Poliacrilato $^{a}$ & Monômero do acrilato \\
\hline Policloropreno $^{\mathrm{a}}$ & Cloropreno \\
\hline Estireno-butadieno $^{\text {a }}$ & $\begin{array}{l}\text { Estireno, buta-1,3-dieno, 4- } \\
\text { vinilcicloexeno }\end{array}$ \\
\hline Poliuretanos ${ }^{\mathrm{c}}$ & $\begin{array}{l}\text { Diisocianato, mono-álcoois, } \\
\text { dióis, compostos cíclicos }\end{array}$ \\
\hline Polietileno $^{c}$ & $\begin{array}{l}\text { Séries homólogas de dienos, } \\
\text { alquenos e alcanos }\end{array}$ \\
\hline Poli(acetato de vinila) ${ }^{\mathbf{b}}$ & Ácido acético \\
\hline Poli(cloreto de vinila) ${ }^{\mathbf{b}}$ & $\mathrm{HCl}$, benzeno \\
\hline Poliamida (Náilon 6) ${ }^{\mathbf{b}}$ & $\varepsilon$-caprolactama \\
\hline Poli(metacrilato de metila) ${ }^{\mathbf{a}}$ & Metacrilato de metila \\
\hline Poli(tetrafluoreteno) ${ }^{\mathbf{a}}$ & Tetrafluoreteno \\
\hline
\end{tabular}

Reações de degradação: ${ }^{\text {a }}$ despolimerização; ${ }^{\mathbf{b}}$ eliminação; ${ }^{\mathbf{c}}$ clivagem aleatória.

Tabela 2. Comparação dos resultados obtidos por IV, ATG e Pi-CGEM na determinação da composição de misturas ternárias de borracha natural $(\mathrm{N})$, borracha estireno-butadiento $(\mathrm{E})$ e borracha butadieno (B). Adaptada da ref. 50

\begin{tabular}{lccc}
\hline Amostra & \multicolumn{3}{c}{ Valor encontrado } \\
& IV & ATG & Pi-CG-EM \\
\hline N50E25B25 & $38 / 22 / 40$ & $18 / 55 / 26$ & $46 / 32 / 22$ \\
N25E50B25 & $22 / 40 / 38$ & $13 / 63 / 24$ & $27 / 49 / 24$ \\
N25E25B50 & $22 / 22 / 55$ & $5 / 80 / 15$ & $22 / 28 / 50$ \\
\hline
\end{tabular}

Schmidt et al. ${ }^{51}$ realizaram estudos sobre quimiotaxonomia de microorganismos por meio de pirólise analítica, avaliando a influência de vários parâmetros (pressão, temperatura e tempo de pirólise) nas áreas dos picos referentes aos compostos oriundos da pirólise dos microorganismos (Escherichia coli, Micrococcus luteus e Bacillus megaterium). A metodologia empregada mostrou-se alternativa na contagem de bactérias. Os pirogramas obtidos para os três tipos de bactérias estudados foram analisados, encontrando-se sinais característicos (biomarcardores) de tipos diferentes de bactérias, como o ácido tetradecanóico, tridecan2-ona e dodecanal, que são compostos usados para distinguir bactéria gram-negativa (E. coli) de outras bactérias gram-positivas, como $M$. luteus e B. megaterium. ${ }^{52}$

Alves et al.$^{53}$ aplicaram a pirólise analítica para determinar o conteúdo de lignina em madeira de duas espécies de pinho Marítimo (Pinus pinaster e Picea abies). Os resultados obtidos com a pirólise analítica foram compatíveis com os teores de lignina Klason determinados pelo método (TAPPI T 222 OM-88), que é largamente utilizado como padrão para esse tipo de análise. ${ }^{54}$

\section{APLICAÇÕES}

\section{Amostras biológicas}

A pirólise analítica tem sido aplicada em estudos de materiais biológicos há vários anos, conforme descrito por Gutteridge e Norris. ${ }^{9}$ Abbey et $a l .{ }^{55}$ distinguiram tipos de Klebsiella pneumoniae por meio de pirogramas característicos. Além de eficiente e segura, a metodologia empregada mostrou-se mais rápida que as técnicas tradicionais na classificação de vários tipos desses microorganismos. Smith et al..$^{56}$ encontraram um marcador químico para discernir o estreptococo do grupo A daquele do grupo $\mathrm{B}$, concluindo que o composto presente no grupo $\mathrm{A}$ e ausente no grupo B era derivado do carboidrato glucitol.

Outros trabalhos com vários tipos de amostras biológicas têm sido feitos envolvendo enzimas, ${ }^{57}$ esteróides, ${ }^{58}$ bactérias $^{51,59}$ e fungos. ${ }^{60}$ Destaca-se o estudo realizado por Tan et al.${ }^{61}$ aplicando pirólise analítica na identificação de pacientes com leucemia. Nesse trabalho, células mononucleares e plasma da medula óssea de 65 pessoas foram estudados. Entre essas, havia 30 indivíduos com leucemia, 12 com doenças hematológicas, 4 com mieloma múltiplo, 1 com histocitose maligna e 18 saudáveis, os quais foram analisados por experimentos de Pi-CG de alta resolução.

Os pirogramas das células leucêmicas apresentaram diferenças significativas em relação aos de células com outras doenças hematológicas e de células saudáveis. Observou-se que quanto maior a intensidade do pico em 3,7 min, maior a incidência de doença. Os pirogramas das células de pessoas saudáveis não apresentam esse pico. Já aqueles de células de uma pessoa com leucemia têm o sinal (em 3,7 min) mais acentuado que aqueles das células de uma pessoa em tratamento. As células de pessoas com outras doenças hematológicas apresentam pirogramas com esse sinal em menor intensidade. Apesar de ter sido realizado como projeto-piloto, o trabalho ainda avaliou subtipos de células leucêmicas em vários estágios da doença. Essa técnica mostrou-se extremamente simples, se comparada a outras já utilizadas, e muito eficiente como método de diagnóstico de células leucêmicas. Outros picos com tempo de retenção em 9,7, 10,5 e 11,7 min também se mostraram importantes no diagnóstico dos pacientes. Segundo os autores, esses picos são provavelmente relativos a fragmentos de RNA e DNA das células leucêmicas mononucleares. ${ }^{61}$

\section{Materiais poliméricos sintéticos}

Ohtani et al..$^{62}$ obtiveram informações microestruturais sobre poliolefinas e, posteriormente, Wang e Smith ${ }^{63}$ desenvolveram um método para determinar a composição e microestrutura de polietilenos clorados com porcentagens de cloro que variam de 25 a $48 \%$ em massa. A composição foi determinada pela análise dos picos referentes aos compostos hex-1-eno, cicloexeno, cicloexa-1,3-dieno e benzeno formados durante a pirólise. Os resultados encontrados foram similares aos obtidos por estudos de ressonância magnética nuclear.

Borrachas sintéticas ou naturais representam uma importante classe de materiais utilizados em trabalhos da pirólise. ${ }^{64}$ Phair e Wampler ${ }^{65}$ publicaram uma revisão de Pi-CG-EM com resultados de pirólise de ampla variedade de borrachas e outros materiais contendo borrachas, incluindo poliisopreno, polibutadieno, copolímeros do estireno, butadieno e polidimetilsiloxano. Na revisão de Wampler, ${ }^{29}$ pode-se observar a ilustração do pirograma de amostras de borrachas pirolisadas a 610 ${ }^{\circ} \mathrm{C}$, produzindo principalmente monômeros de estireno e isopreno. Vale ressaltar que em análises desses tipos de borrachas também foi detectada a presença de dímeros dessas substâncias.

\section{Estereorregularidade de polímeros}

O poliestireno é um dos polímeros mais utilizados pelas indústrias, por ser transparente e de fácil manuseio, ter alta resistência à insolação, além de outras propriedades. Ele pode ser classificado como isotáctico, sindiotáctico e atáctico, dependendo da sua estereorregularidade. A taticidade é fator que influencia muito nas propriedades do polímero, como a alta estereorregularidade do poliestireno sindiotáctico, que reflete a expressiva resistência ao calor e à tensão, em relação às outras categorias. Normalmente, a taticidade de um polímero é estudada por experimentos de ressonância magnética nuclear (RMN) ${ }^{66}$ Porém, essa técnica requer 
grande quantidade de amostra, além da realização do experimento demandar muito tempo (usualmente mais de $8 \mathrm{~h}$ ). Dessa forma, métodos analíticos mais rápidos e sensíveis para a determinação da taticidade de polímeros são de grande interesse para indústrias de polímeros para fins de controle de qualidade. A pirólise analítica tem-se mostrado muito eficiente nesses quesitos, pois necessita de microgramas da amostra para as análises e, em geral, os experimentos não ultrapassam 100 min. A sua caracterização é realizada por meio de estruturas de diastereoisômeros, como os tetrâmeros e pentâmeros formados durante a pirólise. ${ }^{44}$

Na Figura 9, observa-se que os principais produtos da pirólise são o monômero do estireno (com aproximadamente $80 \%$ de todas as áreas dos picos), os dímeros (6\%) e os trímeros (5\%). Embora na estrutura do trímero exista um átomo de carbono assimétrico, a identificação desse composto não fornece qualquer informação sobre a taticidade do polímero. As áreas dos picos relativos aos diastereoisômeros identificados foram interpretadas em termos de estereorregularidade das amostras de poliestireno, por comparação com os resultados obtidos por RMN de ${ }^{13} \mathrm{C}$. Como os diastereoisômeros só são observados em estruturas com mais de dois carbonos assimétricos, os tetrâmeros são as menores estruturas possíveis de serem analisadas. Dessa forma, com aumento da intensidade dos sinais, é possível observá-los na sua região com tempo de retenção de 80 a 85 min. Na Figura 10, estão evidenciadas a expansão dessa região e as diferentes formas de sinais com a mudança de taticidade. Os quatro picos característicos (A, A', B, B') dos pirogramas refletem diferenças de taticidade das amostras. ${ }^{44}$

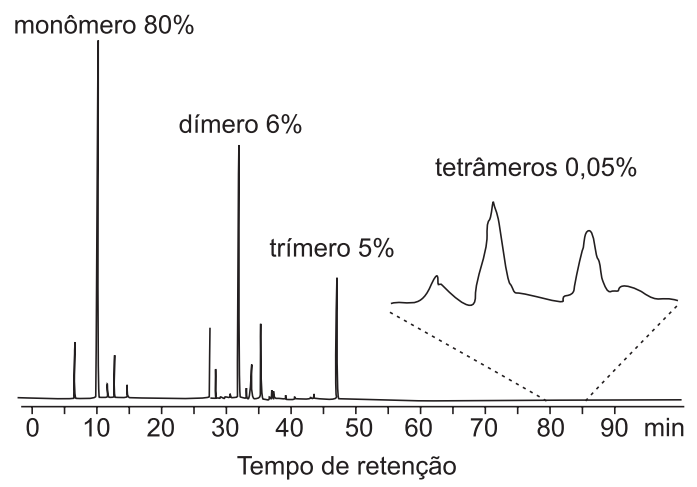

Figura 9. Pirograma de poliestireno atáctico a $600^{\circ} \mathrm{C}^{40}$

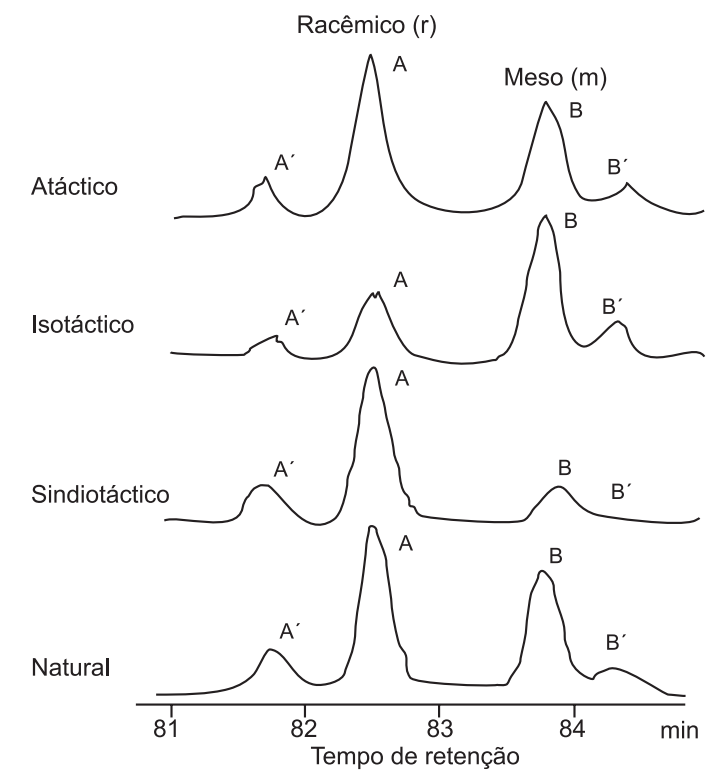

Figura 10. Pirograma parcial de várias amostras de poliestireno na região de picos de tetrâmeros ${ }^{40}$
Na Tabela 3, é apresentada a média dos dados de taticidade para as várias amostras de poliestireno, obtida a partir das áreas relativas dos tetrâmeros em pirogramas e por $\mathrm{RMN}$ de ${ }^{13} \mathrm{C}$.

Tabela 3. Comparação da média de taticidade do poliestireno determinada por Pi-CG-EM e por RMN de ${ }^{13} \mathrm{C}$. Adaptada da ref. 44

\begin{tabular}{lcccc}
\hline $\begin{array}{l}\text { Amostra de } \\
\text { poliestireno }\end{array}$ & \multicolumn{2}{c}{ Pi-CG-EM } & \multicolumn{2}{c}{$\mathrm{RMN} \mathrm{de}{ }^{13} \mathrm{C}$} \\
& $\mathrm{r}(\%)$ & $\mathrm{m} *(\%)$ & $\mathrm{r} *(\%)$ & $\mathrm{m} *(\%)$ \\
\hline Atáctico & 57,6 & 42,4 & 67,5 & 32,5 \\
Isotáctico & 31,0 & 69,0 & 0,0 & 0,0 \\
Sindiotáctico & 84,9 & 15,1 & 98,0 & 2,0 \\
Natural & 57,3 & 42,7 & 66,5 & 33,5 \\
\hline
\end{tabular}

*Diastereoisômeros: racêmicos (r) e meso (m).

Embora os resultados obtidos por Pi-CG não sejam numericamente semelhantes aos obtidos por RMN de ${ }^{13} \mathrm{C}$ (Tabela 3), uma tendência entre eles pode ser observada, pois as porcentagens encontradas para o diastereoisômeros (r) por Pi-CG foram sempre menores que as obtidas por RMN de ${ }^{13} \mathrm{C}$. Já com os diastereoisômeros (m) foi observado o oposto. Esta relação não foi verificada no caso do poliestireno isotáctico em que as porcentagens encontradas para as duas técnicas foram muito diferentes.

Esta diferença entre os dados obtidos pelos dois métodos é atribuída principalmente à estereoisomerização na formação de tetrâmeros por meio da transferência radicalar. Entretanto, uma curva de calibração pode ser preparada pelo uso de amostras-padrão, em que a taticidade é bem definida. Assim, amostras de polímeros de taticidade desconhecida podem ser analisadas em termos de sua estereorregularidade. Essa metodologia é também aplicada a outros polímeros. ${ }^{67,68}$

\section{Amostras geoquímicas}

As amostras geoquímicas são matrizes de difícil análise pelos métodos analíticos tradicionais, devido à estrutura polimérica complexa. ${ }^{27}$ Neste cenário, a pirólise analítica constitui-se um método simples e rápido de se obter informações estruturais da matriz polimérica. ${ }^{27,69}$ Destaca-se o trabalho de Seeley et al..$^{70}$ que descreveram um sistema analítico empregando Pi-CG com detecção de emissão atômica para analisar sedimentos e carvão, observando especificamente carbono, enxofre, nitrogênio, oxigênio, arsênio, selênio e fósforo. Os dados obtidos por esses autores foram utilizados na avaliação do estágio evolucionário das amostras. Empregando uma técnica similar, Stankiewicz et al. ${ }^{71}$ estudaram as cutículas de fósseis de invertebrados. Os resultados obtidos permitiram separar em duas classes distintas: as que produzem compostos aromáticos e as que produzem substâncias alifáticas.

Outra aplicação da técnica Pi-CG corresponde à análise de constituintes insolúveis encontrados em fontes de combustíveis, denominados querógenos. ${ }^{72-75}$ Devido à dificuldade de solubilização, esse tipo de amostra é de difícil estudo pelas técnicas usuais de análise. ${ }^{76,77}$ No desenvolvimento da técnica, foi usado o padrão interno polimérico descrito por Senftle et al.,$^{78}$ e, nos pirogramas dos querógenos avaliados foi observada uma ampla distribuição de hidrocarbonetos de cadeia longa. ${ }^{73,79}$ Recentemente, Fabbri e Vassura ${ }^{80}$ investigaram os níveis de hidrocarbonetos policíclicos aromáticos (HPA) liberados a partir de pirólise analítica off-line de matéria orgânica, como pneu, madeira e carvão. Neste trabalho, o pirolisador de filamento resistivamente aquecido foi adaptado a um cartucho contendo um adsorvente. Os compostos recolhidos pelo adsorvente foram extraídos com diclorometano e analisados por CG-EM. Os melhores resultados para as figuras de mérito (precisão, repetibilidade, limite de quantificação e 
linearidade) foram encontrados para HPA com massa molar menor que $202 \mathrm{Da}$. Embora mais lenta, a pirólise off-line elimina perdas de massa provocada pela interface da configuração on-line.

Trabalhos envolvendo amostras de carvão têm detectado compostos de enxofre a partir da pirólise dessas amostras. O experimento adotou a técnica Pi-CG com detecção simultânea por ionização em chama (FID) e detecção fotométrica. ${ }^{81}$ Empregando a mesma técnica, Bonfanti et al.$^{82}$ estudaram a composição química de carvões de diferentes origens geográficas e sugeriram uma classificação baseada nas análises da componente principal e hierárquica. Nesse trabalho, o pirolisador foi acoplado a um cromatógrafo a gás com detectores seletivos a nitrogênio e fósforo (NPD) e detector por ionização em chama (FID). Murae ${ }^{83}$ estudou amostras de materiais de origem extraterrestre (meteoritos) por pirólise analítica, encontrando compostos aromáticos policíclicos (com até quatro anéis aromáticos). O naftaleno foi o principal constituinte detectado em todas as amostras.

\section{Alimentos e produtos relacionados à agricultura}

$\mathrm{Na}$ agricultura, destacam-se os estudos envolvendo a química do solo, como o estudo realizado por Ceccanti et al.,${ }^{84}$ que permitiu classificar diferentes tipos de solos com base em sinais específicos (furfural, fenóis e benzeno) nos pirogramas. Análise de materiais poliméricos, como taninos, lignina, ${ }^{85,86}$ carboidratos presente em forragens ${ }^{87}$ e amostras de híbridos de milho foram estudados por Galleti et al. ${ }^{88} \mathrm{O}$ trabalho resultou no estudo da composição química desses híbridos, o que possibilitou encontrar quatro produtos de pirólise representativos (2-furaldeído, fenol, guaiacol e 2,6-dimetoxifenol), denominados marcadores, que permitiram diferenciar as amostras estudadas.

Hashimoto et al..$^{89}$ usaram a pirólise analítica para diferenciar espécies de ervas, observando em ambas o óleo dessorvido termicamente e os produtos da pirólise resultantes, a partir de partes nãovoláteis. Utilizando procedimento similar, Fortes e Baugh ${ }^{90}$ estudaram o óleo do fruto da Macaúba avaliando a influência da temperatura e do tempo de pirólise no comportamento dos produtos de pirólise. Os principais compostos identificados foram hidrocarbonetos (dieno, alqueno e alcano), aldeídos e ácidos carboxílicos. Este estudo mostrou que o aumento da temperatura (de 700 para $800^{\circ} \mathrm{C}$ ) favoreceu a diminuição da quantidade detectada destes compostos. Da mesma forma, à medida que o tempo de pirólise mudou de 5 para 30 s, observou-se a presença de compostos originários de reações secundárias. Amostras de leite também foram estudadas e agrupadas conforme o teor de proteínas, utilizando Pi-CG e análise multivariada. ${ }^{91}$ Empregando metodologia similar, Guillou et al.$^{92}$ estudaram amostras de manteiga de cacau, leite, vinagre, vinho e queijos.

\section{Amostras ambientais}

Os trabalhos analíticos envolvendo amostras ambientais concentram-se principalmente na determinação de substâncias voláteis em amostras de águas e solo. Entretanto, estudos relacionados a espécies não-voláteis, presentes nestas matrizes, também têm sido realizados por pirólise analítica. ${ }^{93-97}$ Destaca-se o trabalho desenvolvido por Chefetz et al.,$^{98}$ que investigaram a estrutura de ácidos húmicos, resultando na identificação de vários fragmentos de ligninas, ésteres de ácidos graxos, compostos nitrogenados e ésteres de ácidos dicarboxílicos. Os autores compararam as informações com os resultados obtidos por RMN de ${ }^{13} \mathrm{C}$ no estado sólido (CP-MAS), que é um experimento que demanda um tempo de análise relativamente maior e, além disso, as informações estruturais fornecidas por essa técnica são limitadas. Verificou-se que a Pi-CG-EM permitiu estudar com mais detalhes as estruturas de ácidos húmicos.

\section{Obras de arte}

A análise da composição química de pigmentos, colas, vernizes e tintas são os principais alvos da pirólise analítica em amostras de materiais artísticos. ${ }^{99-104}$ Destacam-se os trabalhos de Chiavari et al. ${ }^{105}$ e Chiavari et al. ${ }^{106}$ que estudaram oito tipos de resinas naturais (sandáraca, Manila copal, colofônio, terebentina de Veneza, terebentina de Strasbourg, dammar, mastic e verniz) utilizando hexametildissilazano (HMDS) como agente derivatizante. A análise dos produtos de pirólise derivatizados revelou compostos característicos de cada tipo de resina, denominados de marcadores. Por exemplo, o ácido sandaracopimárico foi o principal constituinte da resina sandáraca; já os ácidos pimáricos e abiéticos foram compostos típicos de resinas Pinaceae.

Objetos de âmbar foram estudados no intuito de diferenciar âmbar báltico e não-báltico, por meio da pirólise analítica acoplada à análise da componente principal. Os resultados revelaram que somente o âmbar báltico contém ácido succínico, detectado no pirograma como anidrido succínico. ${ }^{107}$

Recentemente, Piccirillo et al. ${ }^{108}$ usaram óleos secativos (utilizados em tintas e vernizes) para comparar três metodologias de derivatização, sendo uma off-line (trimetilsilildiazometano) e duas on-line (hidróxido de tetrametilamônio - HTMA e hidróxido m-(trifluorometilfenil)trimetilamônio - HTFTMT). Os resultados mostraram que o método on-line apresenta expressiva vantagem, pois não induz à ocorrência de perdas durante a análise. Dentre os agentes derivatizantes, o HTMA apresentou-se mais vantajoso, pois promoveu uma metilação mais eficaz e permitiu a análise de pequenas quantidades de amostra. O método off-line apresentou a desvantagem de necessitar de quantidades maiores de amostras, pois pode ocorrer perda destas.

\section{Ciência forense}

Em estudos forenses, a pirólise analítica é comumente usada na investigação de fragmentos de pinturas automotivas recolhidos em locais de acidentes. Nesse sentido, Wampler et al. ${ }^{109}$ analisaram pinturas de automóveis de épocas diferentes e relataram as modificações químicas encontradas. Em 2005, Burns e Doolan ${ }^{110}$ compararam os dados obtidos por Pi-CG-EM com os obtidos por espectroscopia no infravermelho na identificação de pinturas automotivas. Esses trabalhos revelaram que amostras que apresentaram espectros similares no infravermelho mostraram pirogramas distintos possibilitando, assim, obter mais informações que os espectros no infravermelho. ${ }^{110-112} \mathrm{Re}-$ centemente, Burns e Doolan ${ }^{113}$ avaliaram a aplicação da Pi-CG-EM acoplada a um banco de dados, como ferramenta de identificação de pinturas automotivas.

Outros trabalhos utilizando a pirólise analítica ou os produtos de pirólise para identificar a presença de drogas e seus metabólicos no sangue, na urina ou em tecidos humanos têm sido feitos ${ }^{114-118}$. Neste sentido, Mitsui et al. ${ }^{119}$ aplicaram a pirólise para estudar narcóticos e sais de alcalóides em urinas de seres humanos. Esses autores estudaram a eficiência da transmissão de calor para a amostra na presença de pó de metais ( $\mathrm{Al}, \mathrm{Fe}, \mathrm{Cr}, \mathrm{Zn}, \mathrm{Mn}, \mathrm{Ni}$ e $\mathrm{Cu}$ ) e sais inorgânicos $\left(\mathrm{Na}_{2} \mathrm{CO}_{3}\right.$, $\mathrm{KI}$ e $\left.\left(\mathrm{NH}_{4}\right)_{2} \mathrm{SO}_{4}\right)$. Outros parâmetros, como tempo e temperatura de pirólise, também foram investigados.

Além de amostras de pinturas e resíduos de drogas, os laboratórios forenses têm-se aprimorado no estudo de materiais poliméricos, como fibras. Destaca-se o trabalho de Almér, ${ }^{120}$ que analisou 95 fibras de poliacrilonitrila, 63 tipos de acrílicos e 22 modacrílicos, estabelecendo nove grupos de acrílicos e seis de modacrílicos, através dos resultados obtidos da pirólise analítica. Empregando técnica semelhante, Causin et al. ${ }^{121}$ estudaram fibras de poliacrilonitrila. Embora estas fibras apresentem propriedades e estruturas semelhantes, os produtos de 
pirólise obtidos foram analisados por análise multivariada (análise da componente principal), permitindo encontrar diferenças significativas entre as diversas fibras estudadas. Os autores destacaram a importância deste estudo em investigações criminais.

\section{Análise de produtos da madeira}

Uma das áreas em constante crescimento é a das análises de materiais originários de madeira como lignina, ${ }^{122}$ polpa celulósica, ${ }^{123-125}$ extrativos e pitch. ${ }^{126-129}$ Muitas pesquisas sobre a lignina têm sido realizadas para identificar a estrutura de derivados guaiacil (G) e siringil (S), visando determinar o valor da relação $S / G$ deste tipo de macromolécula. ${ }^{130-137} \mathrm{~A}$ aplicação dessa técnica tem demonstrado que a pirólise analítica é ferramenta muito eficaz na avaliação da qualidade da madeira destinada à polpação.

Alguns estudos mais recentes nessa área têm utilizado agentes derivatizantes como o hidróxido de tetrametilamônio (HTMA) e acetato de tetrametilamônio (ATMA). ${ }^{132,138-140}$ González-Vila et al. ${ }^{141}$ estudaram a influência da derivatização na obtenção dos pirogramas, observando que a presença de agentes derivatizantes melhorava expressivamente a resolução dos sinais dos pirogramas de extrativos e polpas celulósicas contaminadas com pitch. Os dados obtidos foram comparados com os encontrados por RMN de ${ }^{13} \mathrm{C}$ no estado sólido (CP-MAS) e infravermelho, tendo sido observado que a Pi-CG-EM fornecia mais informações que as outras duas técnicas. A principal vantagem da $\mathrm{Pi}-\mathrm{CG}-\mathrm{EM}$ em relação às técnicas espectroscópicas é que em baixas quantidades os sinais de impurezas são mais fáceis de serem detectados e identificados.

Estudos envolvendo a identificação e quantificação de extrativos lipofílicos de madeira têm sido feitos visando relacioná-los com a formação do pitch (depósito adesivo e muito pegajoso de origem vegetal ou artificial, formado durante o processo em várias operações unitárias da fábrica), em virtude do grande problema que este representa dentro das fábricas de papel e celulose. ${ }^{40,127,133,134}$

Del Río et al. ${ }^{142}$ aplicaram a Pi-CG-EM para analisar amostras de pitch e de pintas de polímeros sintéticos presentes em diferentes polpas celulósicas. No pirograma obtido foi identificado um sinal referente ao fragmento de polímero sintético.

A análise dos espectros de massas dos compostos detectados no pirograma indicou que o principal componente da impureza é o dipenteno (dímero do isopreno), confirmando que a contaminação é originária de borracha sintética de poliisopreno. Como a Pi-CG-EM mostrou-se uma técnica muito simples, de alta reprodutibilidade e sensibilidade, Del Río et al. ${ }^{143}$ publicaram um estudo completo, em que analisaram mais de 50 amostras de impurezas de polpa de uma fábrica portuguesa de polpa celulósica. A pesquisa visou encontrar a origem dessas pintas e avaliar a classificação visual realizada pelos técnicos da fábrica. Observou-se que várias das amostras de impurezas encontradas, classificadas pelos técnicos como pintas de resinas, foram identificadas como contaminação por borrachas (polímeros sintéticos). Os pirogramas publicados nesse trabalho atualmente auxiliam como impressões digitais (fingerprint), nos trabalhos de identificação da fonte de contaminação de polpas de celulose.

Em um trabalho recente, a pirólise analítica associada à análise da componente principal mostrou ser um método eficaz e rápido na diferenciação de amostras de madeiras geneticamente modificada. ${ }^{144}$ Neste trabalho, os produtos de pirólise da lignina da madeira influenciaram significativamente na diferenciação dos clones.

\section{CONCLUSÃO}

A técnica da pirólise acoplada à cromatografia em fase gasosa e à espectrometria de massas é uma poderosa ferramenta analítica de aplicação em várias áreas da ciência, como apresentado nesta revisão. Vale destacar que, em muitos casos, esta técnica mostrou-se essencial devido à facilidade de interpretação dos dados e ao seu baixo custo em relação a outras existentes.

Embora menos precisa que a de filamento, a pirólise em microforno apresenta relativa vantagem, por ter custos menos elevados e não ocorrem aquecimento gradativo da amostra. Com isso, não ocorre mudanças estruturais na amostra original, durante o aquecimento.

A aplicabilidade e as vantagens da pirólise analítica em relação a outras técnicas de análise estão diretamente relacionadas à tendência mundial de inserir cada vez mais produtos com composição polimérica no mercado. Como conseqüência, certamente, nos próximos anos, a pirólise analítica ganhará posição de maior destaque no cenário acadêmico, ao lado de outras técnicas de identificação já consagradas.

\section{REFERÊNCIAS}

1. Uden, P. C.; Pure Appl. Chem. 1993, 65, 2405.

2. Robert, A. W. J.; Rose, M. E.; Mass spectrometry for chemists and biochemists, $2^{\text {nd }}$ ed., Cambridge: Cambridge (UK), 1990.

3. Irwin, W. J.; J. Anal. Appl. Pyrolysis 1979, 1, 3.

4. Levy, R. L.; Chromatogr. Rev. 1966, 8, 48.

5. Ericson, I.; J. Anal. Appl. Pyrolysis 1985, 8, 73.

6. Tsuge, S.; Ohtani, H. Em Mass Spectrometry of Polymers; Montaudo, G.; Lattimer, R. P., eds.; CRC Pres: Boca Raton, 2002, cap. 3.

7. Wang, F. C.; J. Chromatogr., A 1999, 843, 413.

8. Hosaka, A.; Watanabe, C.; Tsuge, S.; J. Anal. Appl. Pyrolysis 2007, 78, 452.

9. Gutteridge, C. S.; Norris, J. R.; J. Appl. Bacteriol. 1979, 47, 5.

10. Bart, J. C. J.; J. Anal. Appl. Pyrolysis 2001, 58-59, 3.

11. Madorsky, S. L.; Straus, S.; Ind. Eng. Chem. 1948, 5, 848.

12. Wall, L. A.; J. Res. Natl. Bur. Std. 1948, 41, 315.

13. Bradt, P.; Dibeler, V. H.; Mohler, F. L.; J. Res. Natl. Bur. Std. 1953, 50, 201.

14. Davison, W. H. T.; Slaney, S.; Wrang, A. L.; Chem. Ind. 1954, 30, 1356.

15. Lehrle, R. S.; Robb, J. C.; Nature 1959, 183, 1671.

16. Radell, E. A.; Strutz, H. C.; Anal. Chem. 1959, 31, 1890.

17. Martin, S. B.; J. Chromatogr. 1959, 2, 272.

18. Vallmin, J.; Kriemler, P.; Omura, I.; Seible, J.; Simon, W.; Microchem. J. 1966, 11, 73 .

19. Dandneau, R.; Zerner, H. E.; J. High Res. Chromatogr. Commun. 1979, 2,351 .

20. Tsuge, S.; J. Anal. Appl. Pyrolysis 1995, 32, 1.

21. Tsuge, S.; Ohtani, H.; Pyrolysis Gas Chromatography of High Polymers: Fundamentals and Data Compilation, Techno-Systems: Tokyo, 1989.

22. Jin, X.; Luo, Y. F.; Chinese Science and Technology, Publ. Co.: Beijing, 1992.

23. Blazso, M.; J. Anal. Appl. Pyrolysis 1997, 39, 1.

24. Wampler, T. P.; J. Anal. Appl. Pyrolysis 2004, 71, 1.

25. Wampler, T. P.; Applied Pyrolysis Handbook, Marcel Dekker: New York, 1995.

26. Montaudo, G.; Lattimer, R. P.; Mass spectrometry of Polymers, CRC Press: Boca Raton, 2002.

27. Irwin, W. J.; Analytical Pyrolysis - A comprehensive guide, Marcel Dekker: New York, 1982, vol. 22.

28. Levy, R. L.; J. Gas Chromatogr. 1967, 5, 107

29. Wampler, T. P.; J. Chromatogr., A 1999, 842, 207.

30. Wampler, T. P.; Levy, E. J.; J. Anal. Appl. Pyrolysis 1987, 12, 75.

31. Haney, M. A.; Johnston, D. W.; Clampitt, B. H.; Macromolecules 1983, $16,1775$.

32. Poutsma, M.; J. Anal. Appl. Pyrolysis 2005, 73, 159. 
33. Lattimer, R. P.; Pausch, J. B.; Meuzelaar, H. L. C.; Macromolecules 1983, 16, 1896.

34. Atkinson, D.; Cook, S.; Lehrle, R.; Eur. Polym. J. 1992, $28,367$.

35. Gardner, P.; Lehrle, R.; Turner, D.; J. Anal. Appl. Pyrolysis 1993, 25, 11.

36. McNeill, I. C.; J. Anal. Appl. Pyrolysis 1997, 40-41, 21.

37. Marongiu, A.; Faravelli, T.; Bozzano, G.; Dente, M.; Ranzi, E.; J. Anal. Appl. Pyrolysis 2003, 70, 519.

38. Tsuge, S.: Ohtani, H.; Applied Pyrolysis Handbook, Marcel Dekker: New York, 1995.

39. Bhadury, P. S.; Singh, S.; Sharma, M.; Palit, M.; J. Anal. Appl. Pyrolysis 2007, 78, 288

40. Silvério, F. O.; Barbosa, L. C. A.; Pilo-Veloso, D., resultados não publicados

41. Tsuge, S.; Ohtani, H.; Polym. Degrad. Stab. 1997, 58, 109.

42. Hu, Y.; Li, S.; J. Anal. Appl. Pyrolysis 2007, 78, 32.

43. Kannan, P.; Biernacki, J. J.; Visco Jr, D. P.; J. Anal. Appl. Pyrolysis 2007, 78, 162.

44. Nonobe, T.; Ohtani, H.; Usami, T.; Mori, T.; Fukumori, H.; Hirata, Y.; Tsuge, S.; J. Anal. Appl. Pyrolysis 1995, 33, 121.

45. Smith, C. Em Handbook of instrumental techniques for analytical chemistry; Frank, S., ed.; Prentice Hall PTR: Upper Saddle River, 1997, cap. 49

46. Anderson, E. M.; Ericsson, I.; J. Anal. Appl. Pyrolysis 1979, 1, 27.

47. Meier, D.; Faix, O.; Methods in Lignin chemistry, Springer Series in Wood Science: Springer-Verlag: Heidelberg, 1992.

48. Haken, J. K.; J. Chromatogr., A 1998, 825, 171

49. Liebman, S. A.; Levy, E. J.; Pyrolysis and CG in polymer analysis, Marcel Dekker: New York, 1985, vol. 29.

50. Lee, Y. S.; Lee, W.; Cho, S. G.; Kim, I.; Há, C. S.; J. Anal. Appl. Pyrolysis 2006, 1, 27.

51. Schmidt, H.; Tadjimukhamedov, F. K.; Douglas, K. M.; Prasad, S.; Smith, G. B.; Eiceman, G. A.; J. Anal. Appl. Pyrolysis 2006, 76, 161.

52. Snyder, A. P.; Dworzanski, J. P.; Tripathi, A.; Maswadeh, W. M.; Wick, C. H.; Anal. Chem. 2004, 76, 6492.

53. Alves, A.; Schwanninger, M.; Pereira, H.; Rodrigues, J.; J. Anal. Appl. Pyrolysis 2006, 76, 209.

54. Schwanninger, M.; Hinterstoisser, B.; Holzforschung 2002, 56, 161.

55. Abbey, L. E.; Highsmith, A. K.; Moran, T. F.; Reiner, E. J.; J. Clin. Microbiol. 1981, 13, 313.

56. Smith, C. C.; Morgan, S. L.; Parks, C. D.; Fox, A.; Pritchard, D. G.; Anal. Chem. 1987, 59, 1410.

57. Danielson, N. D.; Glajch, J. L.; Rogers, L. B.; J. Chromatogr. Sci. 1978, 16,455 .

58. Menger, F. M.; Hopkins, J. J.; Cox, G. S.; Maloney M. J.; Bayer, F. L.; Anal. Chem. 1978, 50, 1135.

59. Abbas-Hawks, C.; Voorhees, K. J.; Miketova, P.; J. Anal. Appl. Pyrolysis 2006, 76,6

60. Schwarzinger, C.; J. Anal. Appl. Pyrolysis 2005, 74, 26.

61. Tan, L.; Zhong, F.; An, X.; Shen, P.; Chen, B.; Zheng, T.; Long, H.; J. Anal. Appl. Pyrolysis 1995, 32, 187.

62. Ohtani, H.; Tsuge, S.; Ogawa T.; Elias, H. G.; Macromolecules 1984, $17,465$.

63. Wang, F. C.; Smith, P. B.; Anal. Chem. 1997, 69, 618.

64. Wampler T. P.; J. Anal. Appl. Pyrolysis 1989, 15, 187.

65. Phair, M.; Wampler, T. P.; Rubber Work 1997, 215, 30.

66. Kiura, M.; Atarashi, J.; Ichimura, K.; Ito, H.; Ohtani, H.; Tsuge, S.; J. Appl. Polym. Sci. 2000, 78, 2410.

67. Ohtani, H.; Luo, Y. F.; Nakashima, Y.; Tsukahara, Y.; Tsuge, S.; Anal. Chem. 1994, 66, 1438.

68. Nanobe, T.; Tsuge, S.; Ohtani, H.; Kitayama, T.; Hatata, K.; Macromolecules 1997, 30, 4891

69. Iglesias, M. J.; Del Río, J. C.; Laggoun-Défarge, F.; Cuesta, M. J.;
Suárez-Ruiza, I.; J. Anal. Appl. Pyrolysis 2002, 62, 1.

70. Seeley, J. A.; Zeng, Y.; Uden, P.; Eglinton, T. I.; Ericsson, I.; J. Anal. At Spectrom. 1992, 7, 979.

71. Stankiewicz, B. A.; Briggs, D. E.; Evershed, R. P.; Energy Fuels 1997, 11,515 .

72. Larter, S. R.; Senftle, J. T.; Nature 1985, 318, 277.

73. González-Vila, F. J.; Amblès, A.; Del Río, J. C.; Grasset, L.; J. Anal. Appl. Pyrolysis 2001, 58-59, 315

74. van Lieshout, M. P. M.; Janssen, H.; Cramers, C. A.; van den Bos, G. A.; J. Chromatogr., A 1997, 764, 73.

75. Vandenbroucke, M.; Oil Gas Sci. Technol. 2003, 58, 243.

76. Tissot, B. P.; Durand, B.; Espitalie, J.; Combaz, A.; Bull. Am. Ass. Petrol. Geol. 1974, 58, 499

77. Gutjahr, C. C. M.; Geologie Mijnb.1983, 62, 417.

78. Senftle, J. T.; Larter, S. R.; Bromley B. W.; Brown, J. H.; Org. Geochem. 1986, 9,345 .

79. Horsfield, B.; Geochem. Cosmmochim. Acta 1989, 53, 891.

80. Fabbri, D.; Vassura, I.; J. Anal. Appl. Pyrolysis 2006, 75, 150.

81. Almén, P.; Ericsson, I.; Selsbo, P.; J. Anal. Appl. Pyrolysis 1993, 25, 243.

82. Bonfanti, L.; Comellas, L.; Liberia J. L.; Val Honrat-Matalonga, R.; Pich- Santacana, M.; Loes-Pinol, D.; J. Anal. Appl. Pyrolysis 1997, 44, 101.

83. Murae, T.; J. Anal. Appl. Pyrolysis 1995, 32, 65.

84. Ceccanti, J. M.; Alcaniz-Baldellou, M.; Gispert-Negrell, M.; GassiotMatas, M.; Soil Sci. 1994, 142, 83.

85. Galletti, G. C.; Modafferi, V.; Poiana, M.; Bocchini, P.; J. Agric. Food Chem. 1995, 43, 1863.

86. Garnier, N.; Richardin, P.; Cheynier, V.; Regert, M.; Anal. Chim. Acta 2003, 493, 137.

87. Reeves, J. B.; Francis, B. A.; J. Anal. Appl. Pyrolysis 1997, 40-41, 243.

88. Galletti, G. C.; Reeves, J. B.; Bocchini, P.; Muscarella, C. I.; J. Agric. Food Chem. 1997, 45, 1715.

89. Hashimoto, K.; Inoue, T.; Sumida, Y.; Terada, S.; Watanabe, C.; J. High Resolut. Chromatogr. Commun. 1997, 11, 347.

90. Fortes, I. C. P.; Baughb, P. J.; J. Braz. Chem. Soc. 1999, 10, 469.

91. Schmidt, M. A. E.; Radovic, B. S.; Lipp, M.; Harzer, G.; Anklam, E.; Food Chem. 1999, 65, 123.

92. Guillou, C.; Lipp, M.; Radovic, B.; Reniero, F.; Schmidt, M.; Anklam, E.; J. Anal. Appl. Pyrolysis 1999, 49, 329.

93. White, D. M.; Irvine, R. L.; Environ. Monit. Assessment 1998, $50,53$.

94. Leinweber, P.; Schulten, H. R.; J. Anal. Appl. Pyrolysis 1999, 49, 359.

95. Olivella, M. A.; Del Río, J. C.; Palacios, J.; Vairavamurthy, M. A.; de las Heras, F. X. C.; J. Anal. Appl. Pyrolysis 2002, 63, 59.

96. Chen, Y.; Compost Sci.Utilization 2003, 11, 152.

97. Faure, P.; Schlepp, L.; Mansuy-Huault, L.; Elie, M.; Jardé, E.; Pelletier, M.; J. Anal. Appl. Pyrolysis 2006, 75, 1.

98. Chefetz, B.; Tarchitzky, J.; Deshmukh, A. P.; Hatcher, P. G.; Chen, Y.; Soil Sci. Soc. Am. J. 2002, 66, 129.

99. Shedrinsky, A. M.; Wampler, T. P.; Baer, N. S.; J. Anal. Appl. Pyrolysis 1989, $15,393$.

100. Wilchen, H.; Schulten, H.; Fresenius J. Anal. Chem. 1996, 355, 157

101. Stevanato, R.; Rovea, M.; Carbini, M.; Favretto, D.; Traldi, P.; Rapid Commun. Mass. Spectrom. 1997, 11, 286.

102. van den Berg, J. D. J.; Boon, J. J.; Van den Berg, K. J.; Anal. Chem. 1998, 70,1823

103. Chiavari, G.; Gandini, N.; Russo, P.; Fabbri, D.; Chromatographia 1998a, 47, 420

104. Chiavari, G.; Prati, S.; Chromatographia 2003, 58, 543.

105. Chiavari, G.; Fabbi, D.; Galletti, G. C.; Mazzeo, R.; Chromatographia 1995, 41, 273.

106. Chiavari, G.; Fabbi, D.; Prati, S.; Chromatographia 2002, 55, 611 
107. Carlsen, L.; Feldthus, A.; Klarskov, T.; Shedrinsky, A.; J. Anal. Appl. Pyrolysis 1997, 43, 71.

108. Piccirillo, A.; Scalarone, D.; Chiantore, O.; J. Anal. Appl. Pyrolysis 2005, 74, 33.

109. Wampler, T. P.; Bisha, G. A.; Simonsick, W. J.; J. Anal. Appl. Pyrolysis 1997, 40-41, 79.

110. Burns, D.T.; Doolan, K.P.; Anal. Chim. Acta 2005, 539, 145.

111. Burns, D.T.; Doolan, K.P.; Anal. Chim. Acta 2000, 422, 217.

112. Burns, D.T.; Doolan, K.P.; Anal. Chim. Acta 2005, 539, 157.

113. Burns, D.T.; Doolan, K.P.; Anal. Chim. Acta 2006, 571, 25.

114. Bottcher, J.; Bassmann, H.; Erxlben, I.; Schiebel, H. M.; J. Anal. Appl. Pyrolysis 1984, 6, 1.

115. Hida, M.; Mitsi, T.; Minami, Y.; Fujimura, Y.; J. Anal. Appl. Pyrolysis 1995, 32, 197.

116. Lewis, R. J.; Johnson, R. D.; Angier, M. K.; Ritter, R. M.; J. Chromatogr., B: Anal. Technol. Biomed. Life Sci. 2004, 806, 141.

117. Cardona, P. S.; Chaturvedi, A. K.; Soper, J. W.; Canfield, D. V.; Forensic Sci. Int.2006, 157, 46.

118. Gostic, T.; Klemenc, S.; Forensic Sci. Int. 2007, 169, 210.

119. Mitsui, T.; Hida, M.; Fujimura, Y.; J. Anal. Appl. Pyrolysis 1989, 17, 83.

120. Almér, J.; Can. Soc. Forensic Sci. J. 1991, 24, 51.

121. Causin, V.; Marega, C.; Schiavone, S.; Guardia, V. D.; Marigo, A.; J. Anal. Appl. Pyrolysis 2005, 75, 43.

122. Nonier, M. F.; Vivas, N.; Gaulejac, N. V.; Absalon, C.; Soulié, Ph.; Fouquet, E.; J. Anal. Appl. Pyrolysis 2006, 75, 181.

123. Ibarra, D.; Del Río, J. C.; Gutiérrez, A.; Rodríguez, I. M.; Romero, J.; Martínez, M. J.; Martínez, A. T.; J. Anal. Appl. Pyrolysis 2005, 74, 116.

124. Oudia, A.; Mészáros, E.; Simões, R.; Queiroz, J.; Jakab, E.; J. Anal. Appl. Pyrolysis 2007, 78, 233.

125. Cazal, C. M.; Barbosa, L. C. A.; Maltha, C. R. A.; Colodette, J. L.; Reis, E. L.; Mendonça, V. R.; Resumos do $3^{\circ}$ Colóquio Internacional sobre Celulose Kraft de Eucalipto, Belo Horizonte, Brasil, 2007.

126. Cruz, M. P.; Dissertação de Mestrado, Universidade Federal de Viçosa, Brasil, 2004.

127. Cruz, M. P.; Barbosa, L. C. A.; Maltha, C. R. A.; Gomide, J. L.; Milanês, A. F.; Quim. Nova 2006, 29, 459.
128. Silvério, F. O.; Barbosa, L. C. A.; Maltha, C. R. A.; Silvestre, A. J. D.; Pilo-Veloso, D.; Gomide, J. L.; Resumos do $9^{\text {th }}$ European Workshop on Lignocellulosics and pulp, Viena, Áustria, 2006.

129. Silvério, F. O.; Barbosa, L. C. A.; Maltha, C. R. A.; Silvestre, A. J. D.; Pilo-Veloso, D.; Gomide, J. L.; BioRes. 2007, 2, 157.

130. van der Hage, E. R. E.; Mulder, M. M.; Boon, J. J.; J. Anal. Appl. Pyrolysis 1993, 25, 149.

131. Del Rio, J. C.; Gutierrez, A.; Hernando, M.; Landin, P. Romero, J.; Martínez, A. T.; J. Anal. Appl. Pyrolysis 2005, 74, 110.

132. Kuroda, K.; Nakagawa-Izumi, A.; Org. Geochem. 2005, 36, 53.

133. Barbosa, L. C. A.; Demuner, A. J.; Maltha, C. R. A.; Cruz, M. P.; Ventorim, G.; O papel 2005, 9, 68 .

134. Barbosa, L. C. A.; Maltha, C. R. A.; Cruz, M. P.; Belinelo, V. J.; Milanês, A. F.; O papel 2005, 10, 72.

135. Silva, V. L.; Dissertação de Mestrado, Universidade Federal de Viçosa, Brasil, 2006; Lima, C. F.; Barbosa, L. C. A.; Marcelo, C. R.; Silvério, F. O.; Colodette, J. L.; BioRes. 2008, 3, 701.

136. Silva, V. L.; Barbosa, L. C. A.; Maltha, C. R. A.; Colodette, J. L.; Resumos do $3^{\circ}$ Colóquio Internacional sobre Celulose Kraft de Eucalipto, Belo Horizonte, Brasil, 2007.

137. Vinciguerra, V.; Napoli, A.; Bistoni, A.; Petrucci, G.; Sgherzi, R.; J. Anal. Appl. Pyrolysis 2007, 78, 228.

138. Challinor, J. M.; J. Anal. Appl. Pyrolysis 1995, 35, 93.

139. Challinor, J. M.; J. Anal. Appl. Pyrolysis 2001, 61, 3.

140. Klingberg, A.; Odermatt, J.; Meier, D.; J. Anal. Appl. Pyrolysis 2005, 74, 104.

141. González-Vila, F. J.; Gutiérrez, A.; Martin, F.; Verdejo, T.; J. Anal. Appl. Pyrolysis 1997, 40-41, 501.

142. Del Río, J. C.; Gutiérrez, A.; González-Vila, F. J.; Martin, F.; J. Anal. Appl. Pyrolysis 1999, 49, 165.

143. Del Río, J. C.; Hernando, M.; Landin, P.; Gutiérrez, A.; Romero, J.; J. Anal. Appl. Pyrolysis 2003, 68, 251.

144. Meier, D.; Fortmann, I.; Odermatt, J.; Faix, O.; J. Anal. Appl. Pyrolysis 2005, 74, 129. 